secondary victims), providing a glimpse of the horror of losing a family member in this way. The most compelling argument for the continuation of statutory inquiries is that they assist the bereaved family, by letting them know what really happened, and by giving some assurance that efforts will be made to prevent the same thing happening to someone else. This is a powerful argument, but applies equally to all the cases described by Rock. One must welcome any move to improve the treatment of victims, but there is no argument for creating two classes based on whether or not the offender was a psychiatric patient. Why do the relatives of those killed by the intoxicated or by the racist not deserve an inquiry? Also, given the enormity of the loss, it is doubtful that any inquiry could satisfy the bereaved. In a moving annexe to the Mitchell report, the relatives express their feelings and make it clear that they are far from satisfied, even by such an extensive investigation of the case.

The Mitchell killings happened over four years ago. Inquiry reports keep on coming, and political pressures are likely to ensure that they continue for the foreseeable future. Psychiatrists must accept some responsibility for this situation. The profession was slow to recognise the statistical association between schizophrenia and violence, and has still not adopted violent behaviour as a routine outcome measure. Community psychiatrists have sometimes been too quick to take on the psychiatric care of a whole sector, while avoiding questions about the standard of care that can be expected by an individual patient, as one of a caseload of 300 . We should be addressing these matters urgently, and taking back the initiative in dealing with a legitimate public concern. The alternative, an endless series of inquiries and new bureaucracies forced on an unwilling profession, would be unbearable. It would also represent a terrible waste of resources. Governments are fond of telling us that health problems cannot be solved by throwing money at them, and it seems unlikely that this one will be solved by throwing money at lawyers.

Antony Maden, Consultant Forensic Psychiatrist, Denis Hill Unit, Bethlem Royal Hospital, Monks Orchard Road, Beckenham, Kent BR3 3BX

\title{
miscellany
}

\section{New website for teenagers}

To mark the World Mental Health Day on 10 October 1999 the Health Education Authority introduced a new Website to promote self-esteem and positive coping strategies for teenagers. The site www.uzone.org.uk - gives practical advice, deals with mental health issues in a down-to-earth way and is highly interactive, with prizes which include Positive Steps 2000: Surviving the New Millennium, a booklet with celebrity contributions giving tips on dealing with stress. Features of the site include a maze, e-mail postcards to send to a friend and a 'boyzone' and 'girlzone'.

\section{Advice and support for people with dementia}

The Mental Health Foundation has launched the first UK initiative to provide one-to-one advice and support to people with dementia and their carers. The pilot sites for the National Dementia Advice and Support Service will run until December 2002 initially. The service will train and coordinate volunteers to go into the homes of people with dementia and their carers and provide them with practical and emotional support. It will focus on maximising the mental and physical health of both the person with dementia and the carers. The volunteers will provide information and advice on key issues such as access to benefits and accessing increased levels of professional help. They will also aim to equip the carer with the personal coping skills they will need and support them in difficult times. For further information please contact Rachel Clinton or Lesley Warner at the Press Office of the Mental Health Foundation (telephone: 0171535 7421/7422).

Safe Solutions and Training For Mental Health Part 3 are new publications from Pavillion Publishing. Safe Solutions is a new manual which aims to provide practical 'hands on' guidance for anyone within a family mediation service who may find themselves working with people who have either experienced violence, or who have perpetrated violence in their home. The materials are designed to help staff deal with domestic violence safely and fairly by taking them through the various stages of the mediation process. This resource pack is priced at $f 25$. Training For Mental Health Part 3 is a new module of the existing package which provides training sessions in specific areas of mental health. This module, priced at $f 80$, includes the following topics: the service user perspective; coping with a crisis; self-help and complementary approaches; eating, food and eating disorders; and mental health issues for older people. For further information or to order please contact: Pavillion Publishing (Brighton) Ltd, 8 St George's Place, Brighton BN1 $4 Z Z$ (telephone: 01273 623222; fax 01273 625526).

The Mental Health Foundation has produced a new self-help manual for therapists and health professionals to use with their service users. Titled Managing Anxiety and Depression, the manual, which uses cognitive-behavioural strategies, is an easy to use workbook with a quick reference index of problems and helpful exercises. It explains what anxious or depressed feelings are like and how to copy with them, suggests ways of managing panic attacks and explains that medication alone may not be a cure for anxiety or depression, although it may help reduce symptoms. The 45-page, A5-size manual costs f6.50 and is available from the Mental Health Foundation (telephone: 0171 5357441). 